\title{
Meanings and Symbols in The Decorative Motifs and Patterns of Sinudot and Lapoi of The Kimaragang's Costume
}

\author{
Victor B. Pangayan \\ School of Arts \\ Universiti Sains Malaysia \\ Pulau Pinang, Malaysia \\ vicktondig@gmail.com
}

\author{
A.S Hardy B. Shafii \\ School of Arts \\ Universiti Sains Malaysia \\ Pulau Pinang, Malaysia \\ hardy@usm.my
}

\author{
Low Kok On \\ Unit Penyelidikan Warisan Borneo \\ Universiti Malaysia Sabah \\ Kota Kinabalu, Sabah \\ lowkokon@ums.edu.my
}

\begin{abstract}
Kimaragang is the typical ethnic group in Kota Marudu, Sabah. The uniqueness and identity of Kimaragang's community can be regarded in terms of their costumes and textiles - as an ideographic symbol of Kimaragang's people. The Kimaragang traditional costumes are divided into two, sinudot and lapoi. The sinudot a male costume with a classy appearance and masculine, which reflects an active and heroic characteristic, while lapoi worn by women, which indirectly displaying the softness and elegance appearances with the role of symmetry and decorative motif designs. Understanding the Kimaragang traditional costumes is important as a mechanism for emphasizing and preserving their own cultural values. This paper will reviews and explains the authenticity of the indigenous motif and design patterns that were woven on sinudot and lapoi in term of shapes, symbolically designating, and processing techniques applied as the aesthetic characteristics to in-depth perceive the weaving traditions of Kimaragang's with a thorough understanding into the meanings of motifs, patterns and designs in sinudot and lapoi.
\end{abstract}

Keywords: Kimaragang ethnic, traditional costumes, ethnic identity, Sinudot, Lapoi, motifs and designs, aesthetic characteristics

\section{INTRODUCTION}

Costumes are not only act as a decoration, but nearly connected to the history of human life [1]. Costumes are seen as one of the cultural aspects of a society in a period of time and an artistic symbol and creative expression that illustrates the aesthetic value of an ethnic group as reflects in the Kimaragang traditional costumes. The image and structure of Kimaragang ethnic costume indirectly reflect their self-identification through visual appearance. As regards to the relationship between art and costumes, this will reveal the nature of Kimaragang's personality and uniqueness. Besides, the understanding of their spiritual traits and social systems in a culturological context also can be shown. As consequent, important aspects such as materials, colours, motifs and patterns of the costumes are seen as the specified scope of Kimaragang's custome and it is important to express the symbolic and reflects the culture of Kimaragang. The aim of this paper is to determine the Kimaragang's ethnic philosophy of living which embroidered along with the motives and practices on their traditional costume. Thus, it will reveal a rich discernment of the ethnocultural values of the Kimaragang people.

\section{METHODOLOGY}

The informations for this paper were gathered from the fieldwork conducted in the vicinity of Tandek situated in the district of Kota Marudu, Sabah. The majority of Kimaragang's people in the district of Kota Marudu reside in the Tandek area [2], [3]. In order to acquire and collect information related to traditional costumes, in-depth interview was conducted in a natural setting after obtaining the consent of the informant to make face-toface meetings as suggested by Mason [4] and Muthiah [5]. In this field study, elderly people are used as key informants in acquiring and gathering information related to the ornament of sinudot and lapoi. Unstructured questions were asked regarding the meaning and symbols of the motifs and patterns of the Kimaragang's costume.

\section{THE ORGIN OF THE NAME "KIMARAGANG'}

The origin of the name "Kimaragang" is closely related to the name of the textile used to produce their costume in the past. The word "Kimaragang" is derived from the root word "aragang" which means red. According to Jubin Umbang ${ }^{1}$ (63), Kimaragang's ethnic got its name based on the clothes used while attending a festival ceremony [3]. The Kimaragang wearing the attire made from the pinakang cloth which was red. The special red colour of the pinakang cloths, has highlighted the Kimaragang's appearance and attract the attention of the crowd from a distance at that time. The people who saw the incident referred to them as "Ki-maragang" which meant red people and the name remained until now [2], [3]. The pinakang is a textile made from the timbagan (tree bark in

Kimaragang's dialect) and according to Panaga Bin Wanian $^{2}$ (70), usually the process of producing the

\footnotetext{
${ }^{1}$ The late Jubin Bin Umbang (63 years), Village Head, Kg. Togudon, Tandek, Kota Marudu, Sabah. Interviews on: Feb 14, 2012 (Passed away in June 2015)

${ }^{2}$ The late Panaga Bin Wanian (70 years), Kg. Togudon, Tandek, Kota Marudu, Sabah. Interviews on: Aug 21, 2017 (Passed away in Dec 2017)
} 
Pinakang is carried out in the river basin [3], [6]. In addition, the development and modernization of Kimaragang's ethnic especially after the invention of weaving tools, the use of pinakang cloth gradually replaced with nawalan (textiles) cloth. The use of nawalan cloth as the main medium in the Kimaragang costume production still practiced until last from 1881 - 1963 after the arrival of Western power in Marudu bay

[6], [7].

\section{MONINGKOR (SPINNING) AND MANGAWOL (WEAVENING) PROCESSES}

Moningkor (spinning) and mangawol (weavening) are two chain processes in the making of pinakang cloth that has its own artistic values of Kimaragang's weavers (which usually done by women). Their fine craftsmanship will be utilized as the primary material in producing traditional Kimaragang's costume such as sinudot and lapoi in the past [3]. According to Andima Somonul $^{3}$ (75), moningkor is a verb which refers to the process of producing threads known as tiningkor. The spinning of tinigkor in the moningkor process requires four main equipments as shown in Figure 1, namely: i) gapas or cotton are the main ingredients in producing tiningkor, ii) tingkaran which looks like a top and serves as a motor that pulls and rolls the cotton yarn, iii) galun that functions as a base to tingkaran which is shaped like a small plate and iv) rilin do ' kawad is kind of natural wax which produced by local bees and serves as a compressor so that the yarn becomes more solid and dense. It is also the final finishing for the tiningkor (Based on Julia Binti Inatul ${ }^{4}$, 47). Tiningkor that are finished and ready to used can be maintained with its basic colour (white) or can be coloured to enhance the artistic value of the nawalan produced by the method of soaking and boiling with natural dyes, for example tiningkor in black is obtained from the use of specific plant called as to'om and red tiningkor is made form sappang wood [3].

\footnotetext{
${ }^{3}$ The late Andima Binti Somonul @ Osoi (75 years), Former Bobolian, Kg. Tondig, Tandek, Kota Marudu, Sabah. Interviews on: Oct 5, 2012

(Passed away in Feb 2016)

${ }^{4}$ Julia Binti Inatul (63 years). Dance Trainer and Manufacturer of Traditional Kimaragang Costume. Kg. Salimpodon, Pitas Kota Marudu.
}

Interviews on: Mac, 2012

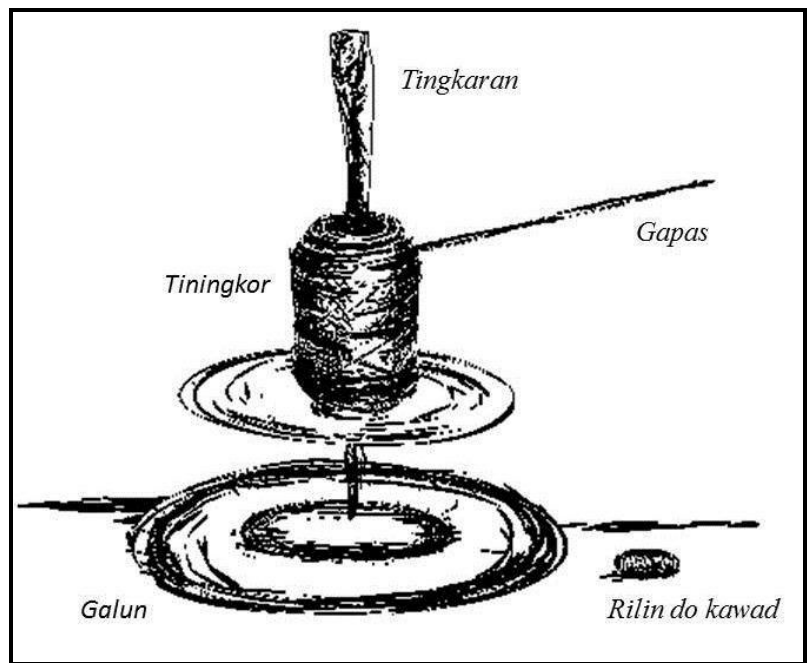

Figure. 1: Moningkor Equipments (Source: Researcher's Collection: resketch)

Once the tiningkor is sufficient, the level of weaving will be extended away to produce nawalan cloth sheet with the weaving machine known as pangawol as shown in Figure 2. The Kimaragang traditional loom structure was built based on four specific tools such as: i) tabit that works as merging of weave bodies with machines placed in the waist belt of weavers to tighten looms and simplify the process of weaving, ii) wiwitan that serves as a weaving needle, iii) tansad is a functional wood used to compress thread embroidery, and iv) lundusan as a yard divider so that the threads are easy to dig through. The process of mangawol and moningkor took a long time and tested the patience and rigour of Kimaragang women in producing a ready made sewing nawalan cloth and producing sinudot and lapoi which will usually be presented at ceremonies

[6].

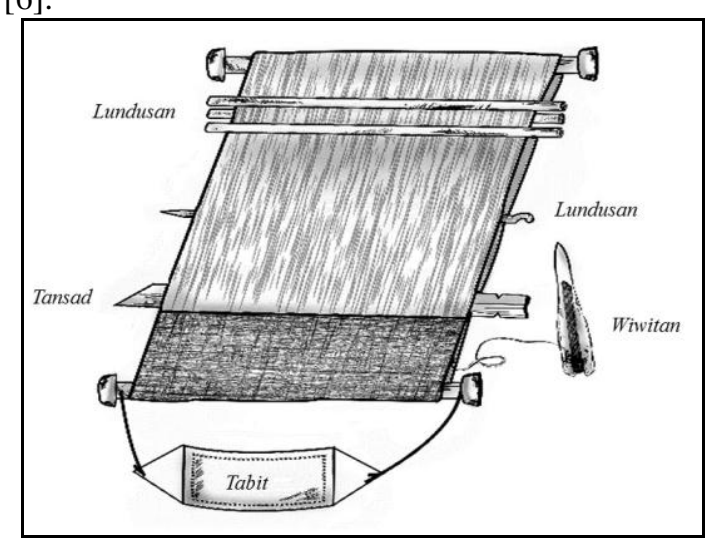

Figure. 2: Mangawol Equipment (Source: Researcher's Collection: resketch)

\section{THE STRUCTURE OF SINUDOT COSTUME}

Sinudot (men's costumes) consist of a suit that is called a sinudot and a pant called botutus. Sinudot refers to the word "sudot" which means "wrinkle" or "have wrinkles" [3]. This wrinkle is usually served as a decoration on the left and right side of the shirt. It is 
also serves as a finishing on the waistline. The front side of sinudot was tied by zig-zag tie technique using tiningkor. Sinudot will be matched with the botutus pants - a dominant pants for Kimaragang men. Botutus is a noun derived from the root word "tutus" in Kimaragang dialect meaning "narrowed down" - where the botutus pants named is based along the pants design that narrows down to the ankle. The sinudot shirt and botutus pants are fitted with the use of tagkos (belts) and sigar (headgear) as shown in Figure 3. According to Bunging Turudang ${ }^{5}$ (78), the man's social status amongst the Kimaragang can be seen from the type of sigar that is worn either as sigar do mandal, rinogian or ginorudaan when fully dressed a sinudot. Each type of sigar worn reveals the symbolic status of the wearer such as, mandal (black and plain) - sigar of common Kimaragang, rinogiann (colourful and patterned) - symbolizes the person from the wealthy family or higher classes, and ginorudaan (with golden lace) - symbolizes the wearer is an influential leader.

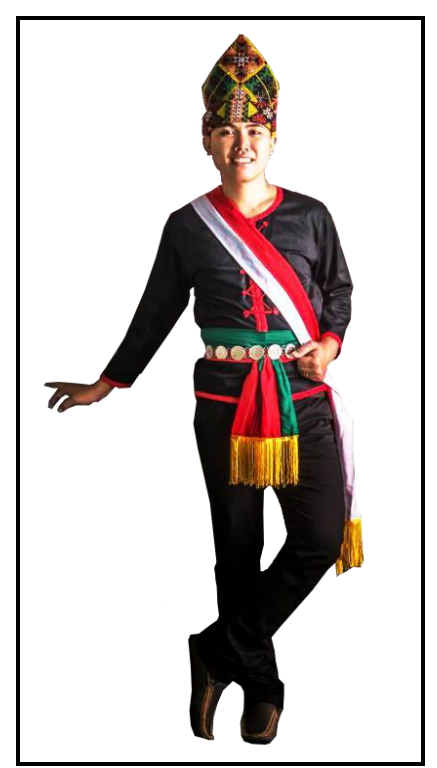

Figure. 3: Sinudot Costume (Source: Researcher's Collection)

\section{THE STRUCTURE OF LAPOI COSTUME}

In the past, Kimaragang woman wore the nawalan cloth by making it as lapoi and tapi' (a piece of cloth that is worn wrapped around the chest) that became a female traditional costume. Lapoi is a cloth-shaped outfit and does not have a latch on the left and right side, and is punched in the centre in order to allow wearer's head entered when wearing the lapoi (see Figure 4). On the inside, Kimaragang women wear tapi' which act as a covering cloth from the chest to the knees.

\footnotetext{
${ }^{5}$ Bunging Bin Turudang (68 years), Kampung Togudon, Tandek, Kota

Marudu, Sabah. Interviews on: Aug 21, 2017
}

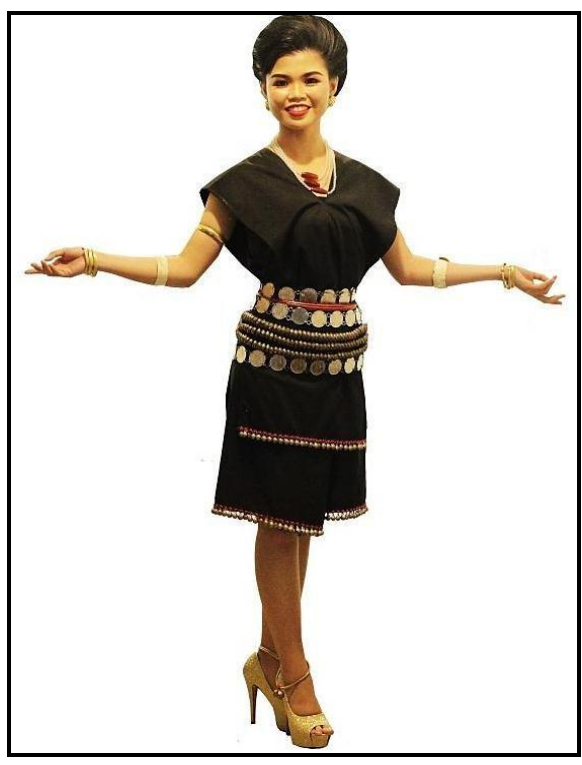

Figure. 4. Lapoi Costume (Source: Researcher's Collection)

Each end of tapi' and lapoi is adorned with a small bell called, giring and some of the lapoi will be decorated with a bunch of triangular arrangement of colourful cloth called linongkitan. At the waist part, it will be paired with torot (belt) comprising taboi toitom (black belt which are made from rattan), taboi taragang (red belt which are made from rattan), galun (rectangular silver belt), sinogoloi (a belt with an arrangement from bronze ring), linantakan (black belt which are made from rattan with silver coating) and himpogot (a belt with an arrangement of the British silver coin). According to Juanas Binti

Makampung ${ }^{6}$ (64), the significant of torot will indicate the wearer marital status such as married or single, and her social status such as wealthy and influential family or an ordinary person.

\section{CHARACTERISTICS OF MOTIF AND PATTERNS OF COSTUMES - SYMBOLIC REPRESENTATION}

The aesthetic value of Kimaragang traditional costume - sinudot and lapoi are not merely determined from the fabrics utilized in the yield of costumes, but also on motifs and patterns that decorated on the sinudot and lapoi. The patterns and motifs found on the sinudot and lapoi are symbolization of the life philosophy, social system, belief and culture of Kimaragang itself. For men's traditional shirt, sinudot, motifs and patterns embroidered on the front of the shirt are shaped with unduk-unduk (sea horse), and limatok (leech) as shown in Table 1 and 2, while the kambang siapu (butterflies) is embroidered on the back of the shirt (see Table 3). Kimaragang emulate the undukunduk due to their nature of always bowed his head and interpreted as a metaphor for showing low self-esteem, but having its own unique, unpredictable

\footnotetext{
${ }^{6}$ Juanas Binti Makampung (62 years), Kg. Togudon, Tandek, Kota Marudu, Sabah. Interviews on: Aug 21, 2017
} 
strengths, wisdoms and advantages, while limatok, seen as an advantages of Kimaragang who can adjust to any situation and continue to survive. Another motif, kambang siapu, reflects on Kimaragang's ethnicity that getting public attention because of their good personality and an interesting personality. These three types of motifs have a slightly different appearance of colours and shapes, but still hold the same symbolic meaning. Figure 3 is derived as a clear and easy-tounderstand summary of the motifs and patterns found on the sinudot.

Table 1: Motifs And Patterns Of Unduk-Unduk (Sea Horse)

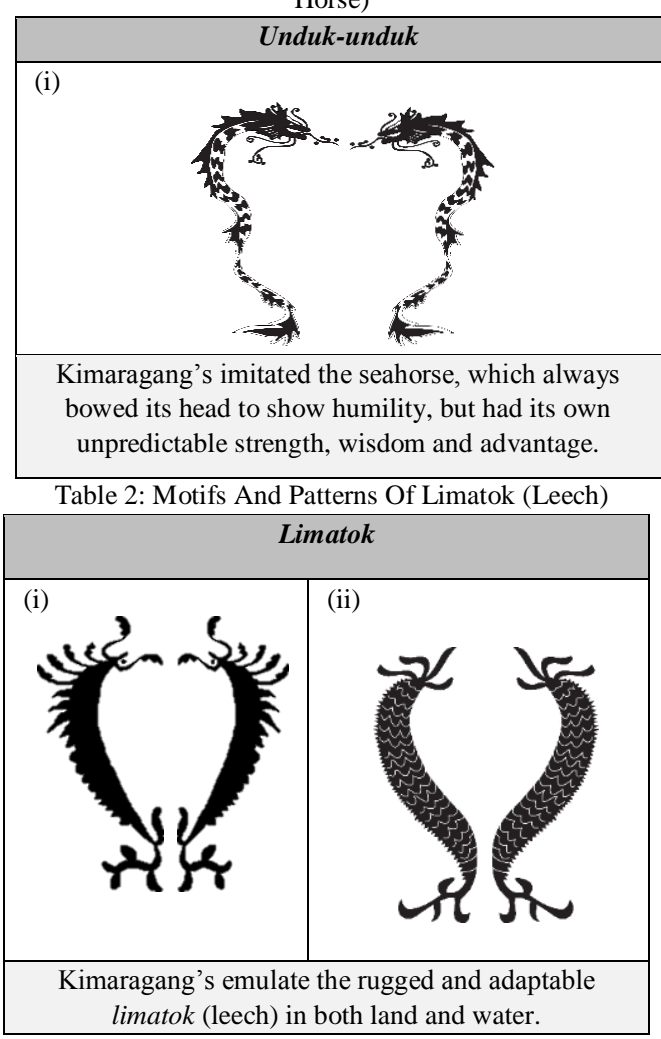

Table 3: Motifs And Patterns Of Kambang Siapu (Butterflies)

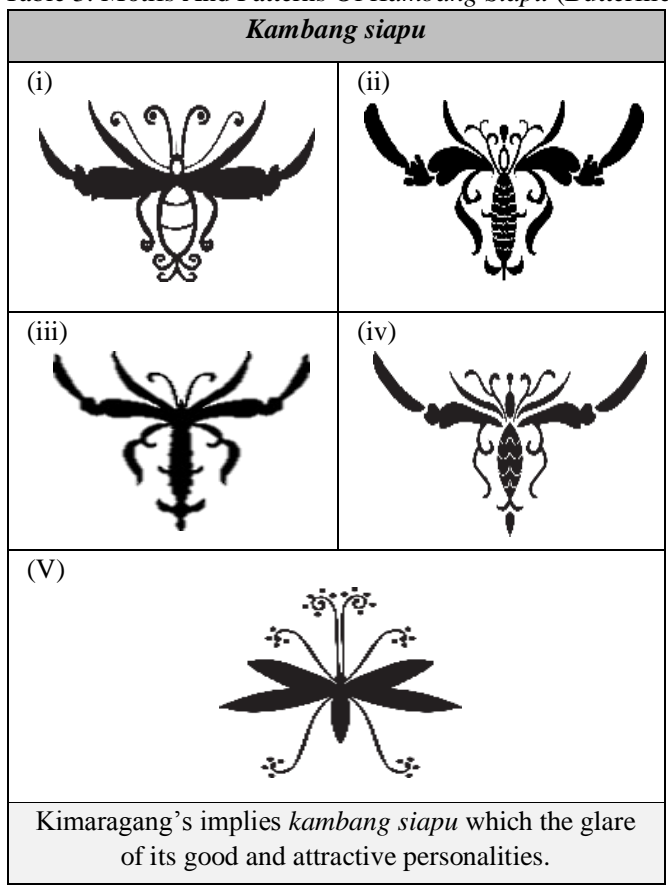

All three motifs are not just visually beautiful, but also express the philosophical values of Kimaragang's ethnic life. When analysed, the character of undukunduk always looked down and clearly reflects the humility value and low self-esteem. For the limatok motif, it is symbolic that Kimaragang's is able to adapt to various conditions and life's hardships. The motif of kambang siapu on the other hand reveals that the Kimaragang people have their own distinctive advantages and privileges because they are always being the focus of the surrounding community as a special ethnic group. Any symbolism is embroidered on the nawalan cloth by using tiningkor yarn that has been dyed. An outstanding and supple combination of colours over the nawalan surface able to highlight the undukunduk, limatok and kambang siapu patterns on sinudot. The combination of colours and patterns on sinudot shirts create harmony and indirectly featuring a cheerful appearance and magnificence of the wearer.

As with sinudot shirts, lapoi dresses are also decorated with hand-made embroidery inspired by nature, such as flowers, paddy, grass and hills. The motifs and patterns composition on the lapoi normally are on the cloth edge such as bottom edge and hemline of the cloth. Motifs and patterns produced by colourful thread embroidery techniques are like wusak (flowers), parai (paddy), linontian (a kind of grass), and linongkitan (triangular arrangement) motifs. Embellished embroidery designs the lapoi are symbolic and representation of the

Kimaragang's philosophy of life itself. Parai motifs that are composed and spotted on lapoi illustrate Kimaragang's life closer to rice cultivation. The wusak motifs show the beauty and softness of Kimaragang ethnic women, while linontian motifs delineate Kimaragang's women are grateful and persevering in pursuing a job. According to Rondikum Binti Yangan ${ }^{7}$ (79), the linongkitan motif (a continuing triangular arrangement) which describes hills and mountains as to denote the experience and knowledge or rinea'at ${ }^{8}$ owned by a woman. All these motifs are styled and embroidered according to the size of the pattern and the suitability of the motif that fills a certain space on lapoi. The motifs layout and placement on lapoi not only produce a harmonious and beautiful lapoi, but as well creating an art full of meanings and symbols based on the Kimaragang's philosophy. Table 4, 5, 6 and 7 present a clear delineation of the wusak (flowers), parai (paddy), linontian (a kind of grass), and linongkitan (triangular arrangement) motifs respectively were expressing the meaning of lapoi dresses.

\footnotetext{
${ }^{7}$ Rondikum Binti Yangang (79 Years), Bobolian, Kg. Nolotan, Tandek, Kota Marudu, Sabah. Interview on June 6, 2017.

${ }^{8}$ Traditional poems memorized by the bobolian or bolungkitas, also known as rinait by other Sabah natives [3], [8].
} 
Table 4: Motifs And Patterns Of Wusak (Flowers)

(i) Wusak

Table 5: Motifs And Patterns Of Parai (Paddy)

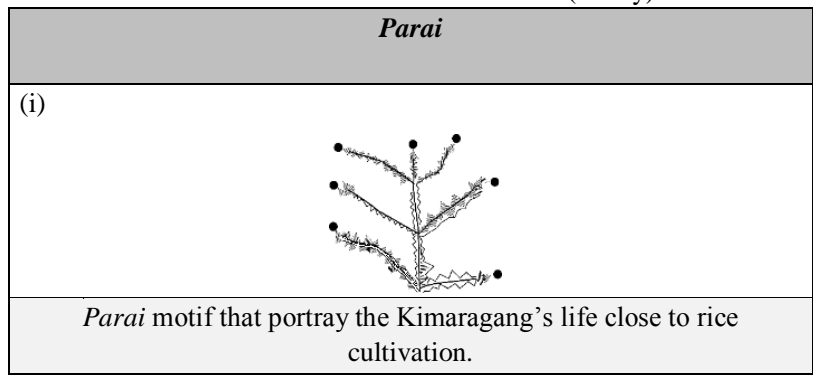

Table 6: Motifs And Patterns Of Linontian (A Kind Of Grass)

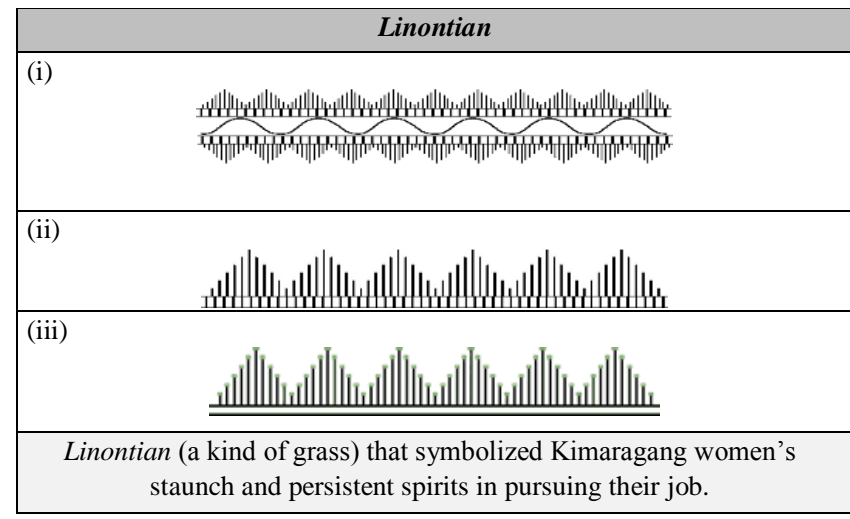

Table 7: Motifs And Patterns Of Linongkitan (Triangular Arrangement)

\begin{tabular}{|l|}
\hline Linongkitan \\
\hline $\begin{array}{c}\text { Linongkitan motif (a continuing triangular arrangement) reveals the } \\
\text { wearer who is skilful in the knowledge of rine'et. }\end{array}$ \\
\hline
\end{tabular}

Based on the above discussion, the motif and pattern structures that decorated on the sinudot and lapoi not only meets the principles of balance, harmony and unity, but they also blended the culture and philosophy of the Kimaragang people. For Kimaragang, they are proud of wearing sinudot (men) and lapoi (women) because they are attractive and beautiful. Indirectly, the Kimaragang play a role as an ambassador who exhibit their culture and philosophy through motifs and patterns that are embroidered on their traditional costumes. Unfortunately, such valuable tradition is faded with modernization and is being forgotten by the young generation nowadays.

\section{CONCLUSION}

Kimaragang traditional costumes made from the weaving of textiles, cloth patterns, colours and motifs of its own in regard reflects the ethnic individuality, cultures and traditional knowledge as part of their historical roots. The traditional costumes can be reckoned as an artwork with the allure presentation and composition motifs and patterns along the textile that responding to audience appreciation known as aesthetics. Each motif and pattern reveals the implied meaning and philosophy of life of the Kimaragang. Thus, understanding and knowledge of the traditional costume in terms of appearance and motif designs are essential and account as cultural treasure that should be carefully guarded by the present generation of Kimaragang's in order such vital information not be lost along with the passing of elderly Kimaragang's future.

\section{ACKNOWLEDGEMENT}

The authors are deeply thankful to all informants for their time, transparency, feedback for gathering a valuable information and knowledge in this research. As well as the people in the district of Kota Marudu reside in the Tandek area is duly appreciated in this phase of the research.

\section{REFERENCES}

[1] B. Payne, and J. Farrel-Beck, "The History of Costume: From Ancient Mesopotamia through the Twentieth" (2nd edition.). New York: Longman, 1992

[2] Low Kok On and J. Pugh-Kitingan," The impact of christianity on traditional agricultural practices and beliefs among the kimaragang of sabah: A preliminary study" Asian Ethnology, vol. 74, no.2, pp. 401-424, 2015.

[3] V. Pangayan. "Tarian Pinakang Etnik Kimargang: Konteks Persembahan dan Perubahan Kostum". Universiti Malaysia Sabah (UMS), Kota Kinabalu, Sabah, 2014

[4] J. Mason, "Qualitative Researching (2nd Edition)". Great Britain: SAGE Publication, 2002

[5] P. Muthiah, "Interview". In M.Puvenesvery, R. Abdul Rahim, R. S. Naidu, M. Badzi, N. F. Mat Nayan, \& N. H. Abd Aziz (Eds.), Qualitative Research: Data Collection \& Data Analysis Techniques, Sintok: Penerbit Universiti Utara Malaysia, pp. 1943, 2008

[6] V. Pangayan, Low Kok On and A. S. H. Shafii. "Kostum Tradisional Etnik Kimaragang di Sabah: Analisis Unsur Perubahan Dan Kearifan Tempatan". In D. M. Naim, M. I Ahmad, A. . H. Shafii, N. Isa, S. C. Lah, \& N. F. L. Ahmad (Eds.), 6th Conferencie

On Local Knowledge (ICLK): Local Wisdom: Universal Heritage, Pulau Pinang, Malaysia: Sakteriat Kearifan Tempatan, Universiti

Sains Malaysia, pp.242-246, 2016

[7] K. Manshur, "Perjuangan Syarif Usman di Kota Marudu", 18301845. Universiti Malaysia Sabah, 2003

[8] J. Pugh-Kitingan, "Kadazan Dusun". Kuala Lumpur: Institut Terjemahan \& Buku Malaysia, 2016

\section{LIST OF INFORMANTS}

\begin{tabular}{|c|l|c|c|l|}
\hline No & \multicolumn{1}{|c|}{ Name } & Age & Sex & Occupation \\
\hline 1 & $\begin{array}{l}\text { Rondikum Binti } \\
\text { Yangang }\end{array}$ & 79 & Female & $\begin{array}{l}\text { Bobolian (ritual } \\
\text { specialist) }\end{array}$ \\
\hline 2 & $\begin{array}{l}\text { Andima Binti } \\
\text { Somonul @ Osoi }\end{array}$ & 75 & Female & $\begin{array}{l}\text { Former } \\
\text { Bobolian(ritual } \\
\text { specialist) }\end{array}$ \\
\hline
\end{tabular}




\begin{tabular}{|c|l|c|c|c|}
\hline 3 & Jubin Bin Umbang & 63 & Male & Village Head \\
\hline 4 & Panaga Bin Wanian & 70 & Male & - \\
\hline 5 & Julia Binti Inatul & 57 & Female & $\begin{array}{l}\text { Dance Trainer and } \\
\text { Manufacturer of } \\
\text { Traditional } \\
\text { Kimaragang } \\
\text { Costume. }\end{array}$ \\
\hline 6 & $\begin{array}{l}\text { Bunging Bin } \\
\text { Turudang (68 } \\
\text { Tahun }\end{array}$ & 68 & Male & - \\
\hline 7 & $\begin{array}{l}\text { Juanas Binti } \\
\text { Makampung }\end{array}$ & 62 & Female & - \\
\hline
\end{tabular}

